\title{
TECNOLOGIAS COMO RECURSO SEMIÓTICO NO DESENVOLVIMENTO DE ATIVIDADES DE MODELAGEM MATEMÁTICA
}

\section{TECHNOLOGIES AS A SEMIOTIC RESOURCE IN THE DEVELOPMENT OF MATHEMATICAL MODELING ACTIVITIES}

\author{
Karina Alessandra Pessoa da Silva ${ }^{1}$ \\ Paulo Henrique Hideki Araki ${ }^{2}$ \\ Adriana Helena Borssoi ${ }^{3}$
}

\begin{abstract}
Resumo: Neste artigo apresentamos resultados de uma pesquisa em que buscamos evidenciar como a tecnologia se configura como recurso semiótico no desenvolvimento de uma atividade de modelagem matemática. Para isso, nos fundamentamos na tecnologia como aliada no desenvolvimento de atividades de modelagem e na semiótica, mais precisamente, na abordagem dos recursos que proporcionam a produção de signos - os recursos semióticos. Por meio de uma análise qualitativa de cunho interpretativo de imagens e falas transcritas da atividade de modelagem desenvolvida em cinco momentos por uma turma de nono ano do Ensino Fundamental de uma escola do norte do Paraná, evidenciamos que a tecnologia se configurou como recurso semiótico, em certa medida, para possibilitar aos alunos examinar os princípios da situaçãoproblema, definir o problema a ser investigado, visualizar o fenômeno mais de uma vez, produzir dados, visualizar o comportamento dos dados, proporcionando a obtenção, interpretação e validação de uma solução para o problema.
\end{abstract}

Palavras-chave: Educação Matemática; Modelagem Matemática; Semiótica; Atividade experimental investigativa; Canhão de vórtex.

\begin{abstract}
In this paper we present results of a research in which we seek to show how technology is configured as a semiotic resource in the development of a mathematical modeling activity. We base on technology as an ally in the development of modeling activities and in semiotics, more precisely, in the approach of the resources that provide the production of signs - the semiotic resources. Through a qualitative analysis of images and transcribed speeches of the modeling activity developed in five moments by a ninth grade class of the Elementary School of a school in the north of Paraná, we show that the technology has been configured as a semiotic resource in to investigate the principles of the problem situation, to define the problem to be investigated, to visualize the phenomenon more than once, to produce data, to visualize the behavior of the data, and to obtain, interpret and validate a solution for the problem.
\end{abstract}

Keywords: Mathematics Education; Mathematical Modeling; Semiotic; Experimental investigative activity; Vortex cannon.

\footnotetext{
${ }^{1}$ Doutora em Ensino de Ciências e Educação Matemática pela Universidade Estadual de Londrina (UEL). Docente da Universidade Tecnológica Federal do Paraná (UTFPR), Londrina, Paraná, Brasil. E-mail: karinasilva@utfpr.edu.br

${ }^{2}$ Mestrando em Ensino de Matemática pela Universidade Tecnológica Federal do Paraná (UTFPR). Docente da Escola PiuPiu Educação Infantil e Ensino Fundamental, São Sebastião da Amoreira, Paraná, Brasil.E-mail: phh.araki@gmail.com

${ }^{3}$ Doutora em Ensino de Ciências e Educação Matemática pela Universidade Estadual de Londrina (UEL). Docente da Universidade Tecnológica Federal do Paraná (UTFPR), Londrina, Paraná, Brasil. E-mail: adrianaborssoi@utfpr.edu.br
} 


\section{Introdução}

Pesquisas que versam sobre modelagem matemática e a sala de aula têm ganhado espaço na comunidade científica, como sugerem importantes eventos nacionais em suas últimas edições (Conferência Nacional sobre Modelagem na Educação Matemática CNMEM, Encontro Paranaense de Modelagem na Educação Matemática - EPMEM e Grupo de Trabalho Modelagem Matemática no Seminário Internacional de Pesquisa em Educação Matemática - SIPEM). A oitava edição do EPMEM, realizada em 2018, que teve como tema "Modelagem Matemática e a sala de aula", visava "simultaneamente, atender às demandas práticas concernentes à Modelagem e abrir um espaço ainda mais estreito e produtivo com os professores da Educação Básica e Ensino Superior, sem perder de vista a devida articulação entre o rigor da pesquisa e as ações desenvolvidas no contexto da sala de aula"4.

A articulação da pesquisa com a sala de aula tem sido o foco de interesse dos membros do Grupo de Estudo e Pesquisa em Modelagem Matemática, Investigação Matemática e Tecnologias (GEPMIT) ${ }^{5}$ do qual os autores deste artigo são integrantes. O GEPMIT está vinculado ao Programa de Mestrado Profissional em Ensino de Matemática da $\mathrm{UTFPR}^{6}$.

Considerando os interesses do GEPMIT, em especial, àqueles alinhados ao uso de tecnologias ${ }^{7}$ no desenvolvimento de atividades de modelagem matemática, bem como na especificidade da formação do professor (um dos autores deste artigo), alunos de uma turma do nono ano do Ensino Fundamental de uma escola privada do norte do Paraná investigaram uma situação-problema cujos dados foram produzidos via uma atividade experimental investigativa.

Segundo Suart e Marcondes (2009, p. 55) em atividades experimentais investigativas, "o aluno se envolve na resolução de um problema e, se mobiliza à procura de uma metodologia para a sua resolução". De posse dessa metodologia, o aluno realiza o manejo de materiais diversos. De certo modo, podemos considerar que o manejo de materiais consiste em um recurso intrínseco para o desenvolvimento de atividades experimentais investigativas e possibilita a produção de signos para a situação-problema

\footnotetext{
${ }^{4}$ Disponível em http://sbemparana.com.br/viiiepmem/. Acesso em: 17 nov. 2018.

${ }^{5}$ https://sites.google.com/view/gepmit

${ }^{6} \mathrm{http}: / /$ portal.utfpr.edu.br/cursos/coordenacoes/stricto-sensu/ppg-mat

7 Ao nos referirmos ao termo tecnologia(s) estamos considerando tecnologia(s) digital(is), salvo outra menção explícita.
} 
investigada. Recursos utilizados para produzir signos são considerados recursos semióticos (MAVERS, 2004).

No contexto de atividades de modelagem matemática, Silva, Vertuan e Silva (2018) afirmam que, para além do manejo de materiais necessários para o desenvolvimento de atividades experimentais investigativas,

\section{[...] há de se buscar reflexões para uma situação-problema por meio de levantamento de hipóteses, realização de análises de dados oriundos de sua realidade, obtendo novas informações que devem ser interpretadas, validadas e comunicadas (p. 70).}

Fundamentados nesse entendimento e ancorados nas assertivas de que a tecnologia pode ser uma aliada para o desenvolvimento de atividades de modelagem matemática é que nos debruçamos em investigar a questão de pesquisa: Como a tecnologia se configura como recurso semiótico no desenvolvimento de uma atividade de modelagem matemática?

Com vistas a apresentar reflexões e inferências sobre tal questão, neste artigo, tomamos como ponto de partida considerações sobre Modelagem Matemática e recursos semióticos, na segunda e terceira seções, respectivamente. Posteriormente, tratamos dos aspectos metodológicos considerados para o desenvolvimento da atividade experimental investigativa e da pesquisa. A quinta seção é destinada para a descrição da atividade desenvolvida, bem como das análises realizadas à luz dos aportes teóricos. Finalizamos com nossas considerações finais e com as referências utilizadas no corpo do artigo.

\section{Modelagem Matemática mediada pela tecnologia}

A Modelagem Matemática “vincula a matemática e questões autênticas do mundo real" (CIRILLO et al., 2016, p. 5). Matemáticos aplicados, bem como profissionais de áreas como biologia, engenharia, finanças, informática e ciências sociais reconhecem que a Modelagem Matemática é essencial para que possam lidar com uma variedade de problemas do mundo real, onde a tarefa principal é traduzir matematicamente um problema.

Cirillo et al. (2016), Almeida Silva e Vertuan (2012), Greefrath e Siller (2017) dentre outros indicam que a tradução do problema por meio da Matemática é a essência da Modelagem Matemática e consiste em esclarecer o problema, identificar variáveis, fazer aproximações, obter um modelo matemático e relatar as conclusões sobre o problema, baseadas nesse modelo.Nesse sentido, "Um modelo matemático é uma representação de um sistema ou cenário que é usado para ganhar compreensão qualitativa 
e/ou quantitativa de algum problema do mundo real e prever o comportamento futuro" (BLISS; FOWLER; GALLUZO, 2014 apud CIRILLO et al., 2016, p. 9).

Para Greefrath e Siller (2017):

\begin{abstract}
Modelos matemáticos e simulações no ensino de Matemática ganharam importância, devido, entre outras coisas, a atual prioridade nos documentos curriculares, o desenvolvimento contínuo de ferramentas digitais e o uso crescente de modelos e simulações para resolver problemas do mundo real (GREEFRATH; SILLER, 2017, p. 529).
\end{abstract}

Entendemos que, em contextos educacionais, atividades de modelagem matemática podem proporcionar aos alunos o protagonismo no estudo de situaçõesproblema. Estimular o senso investigativo dos alunos pode depender da perspicácia do professor, seja para sugerir uma problemática associada aos interesses curriculares, seja para identificar em que reside o interesse dos alunos envolvidos quando se espera que os próprios alunos definam a problemática a ser investigada. Nesse sentido, considerar a presença da tecnologia parece ser estratégico, tendo em vista a proximidade, e mesmo as habilidades, que, em geral, jovens estudantes demonstram com diferentes recursos digitais.

As atividades de modelagem no ensino de Matemática também estão sujeitas, segundo Greefrath e Siller (2017), à influência da tecnologia. "Ferramentas digitais podem ser de grande ajuda para professores e alunos, particularmente em problemas vinculados ao mundo real e a suas discussões" (GREEFRATH; SILLER, 2017, p. 530).

Ao abordar uma situação-problema tomando a modelagem matemática como alternativa pedagógica, o professor deve estar atendo para que as ações dos alunos envolvidos transitem pelas fases (ou etapas, para alguns autores) deinteiração, matematização, resolução, interpretação de resultados e validação.

Para Almeida, Silva e Vertuan (2012) a inteiração, contato inicial com a situação original que se pretende estudar, é a busca por informações que permitem compreender o problema a ser estudado, bem como o modelo real da situação original. A matematização está relacionada à busca e elaboração de uma representação matemática mediadas por relações entre as características da situação e os conceitos, técnicas e procedimentos matemáticos adequados para representar matematicamente estas características. A resolução consiste na construção de um modelo matemático. A interpretação dos resultados indicados pelo modelo matemático implica na análise de uma resolução para o problema, por meio de resultados matemáticos e conclusões sobre o uso. A análise da solução requer avaliação realizada pelos envolvidos na atividade e implica em uma 
validação da representação matemática associada ao problema e sua adequação ao contexto estudado.

A tecnologia pode dar suporte em diferentes fases da modelagem, entendemos que, de diferentes formas. Para Greefrath e Siller (2017), o potencial das ferramentas digitais tem importância particular na descoberta de relações matemáticas, na promoção da compreensão das relações matemáticas, em possibilitar diferentes formas de visualização, no processamento de grandes quantidades de dados, entre outros. Para esses autores, com respeito à descoberta de relações matemáticas, ferramentas digitais são especialmente importantes em experimentos realizados em um modelo real ou matemático (GREEFRATH; SILLER, 2017).

Em atividades experimentais investigativas, a tecnologia pode ser fundamental desde a decisão pela abordagem de um problema. A exemplo disso, mencionamos a análise de vídeos (videoanálise) a partir de experimentos em que se pretende estudar movimento. Avideoanálise é considerada uma tecnologia com potencial para o processo de ensino e de aprendizagem (BRYAN, 2010; BROWN; COX, 2009) e tem ganhado espaço em atividades de modelagem matemática.

Dentre as características do estudo com softwares de videoanálise podemosidentificar na literatura o potencial para oferecer conexão entre experiências escolares e experiências cotidianas; múltiplas representações dos fenômenos em uma mesma tela: vídeo, tabela de dados, gráficos, equações; manipulação dos referenciais e compreensão da influência das escalas na interpretação de fenômenos físicos; análise de mais de um objeto no mesmo sistema, simultaneamente; e, realização de experimentos com baixo custo.

Silva, Borssoi e Almeida (2015), Piffer e Borssoi (2016) e Mendes e Oliveira (2018) discutem situações tanto em contextos em que os alunos participaram do planejamento do experimento e realizaram a produção dos vídeos a serem analisados, quanto situações em que os alunos receberam um arquivo de vídeo a partir do qual precisaram estudar uma problemática. As pesquisas parecem indicar que o protagonismo dos alunos desde a fase de planejamento da atividade experimental investigativa é um fator relevante para a mobilização dos mesmos na busca pela solução do problema.

Para Piffer e Borssoi (2016, p. 15) “a produção dos dados por parte de uma turma, traz significados diferentes aos alunos, daqueles que obtiveram os dados prontos, o que pode causar diferenças nas atitudes e no envolvimento do aluno quanto à situação". 
Do ponto de vista semiótico, Silva, Borssoi e Almeida (2015) inferiram que no desenvolvimento de uma atividade de modelagem

[...] signos adequados foram produzidos pelos intérpretes após o uso da videoanálise que possibilitou a observação dos fenômenos sob a perspectiva dos dados coletados e suas diferentes representações (p. 181).

Assim, para que possamos analisar a tecnologia como recurso semiótico no desenvolvimento de atividades de modelagem, é que se fazem necessárias algumas caracterizações que trazemos na próxima seção.

\section{Recursos semióticos}

A abordagem de objetos matemáticos que emergem do desenvolvimento de atividades de modelagem matemática requer considerar sua natureza simbólica. Os símbolos são signos que estabelecem relações de leis para com os objetos que representam. O estudo e a análise de signos nos remetem ao arcabouço teórico da Semiótica desenvolvida por Charles Sanders Peirce.

O signo, segundo Peirce (2005), é algo que para uma pessoa toma lugar de outra coisa (objeto), não em todos os aspectos desta coisa, mas de acordo com certa forma e capacidade. O objeto é "uma coisa singular existente e conhecida ou que se acredita tenha anteriormente existido ou que se espera venha a existir" (PEIRCE, 2005, p. 48).

Nos estudos realizados sobre a semiótica, Peirce (1972) trata o signo como uma relação entre três elementos — objeto, signo (ou representámen) e interpretante - em que o signo estabelece uma mediação entre objeto e interpretante, perfazendo uma tríade semiótica.

Peirce (1972) afirma que da relação entre signo e objeto resulta outro signo, o interpretante. Esse novo signo é um processo racional que se cria na mente do intérprete, ou seja, na mente interpretadora que produz o interpretante.

A ação própria do signo é determinar um interpretante, ou seja, a ação do signo é a ação de ser interpretado em outro signo. Signo é "qualquer coisa que admita um 'interpretante' - isto é, que seja capaz de dar origem a outros signos” (PEIRCE, 1972, p. 27).

Por exemplo, a ampulheta por si só é um objeto físico confeccionado com, por exemplo, vidro e areia, ou seja, um signo virtual passível de ser interpretado enquanto signo quando encontrado por um intérprete. Dependendo do fundamento (representámen), a ampulheta pode ser um signo interpretado como indicador de tempo, 
um artefato decorativo, um artesanato originado de um trabalho manual. O que devemos destacar, nesse exemplo, é que a ampulheta somente funciona como signo de marcação do tempo, da decoração de um ambiente ou do resultado do trabalho de um artesão se for interpretado como tal. Nesse caso, uma mesma coisa (ampulheta) pode ser diferentes signos. Do mesmo modo, o objeto do signo varia dependendo do interpretante e do fundamento. Em um caso, o tempo é o objeto do signo; em outro, o gosto da pessoa que escolheu a ampulheta como decoração é o objeto do signo; e no outro o artesão é o objeto do signo. Segundo Santaella (2009, p. 45), “o signo não ocorre vazio. Ele está enraizado num vastíssimo mundo de relações com outros signos, com tudo aquilo que muito amplamente chamamos de realidade".

Ao considerarmos o contexto matemático, um aluno ao ver os gestos produzidos pelo seu professor para descrever o trajeto de uma bola lançada para uma cesta de basquete pode relacioná-los ao traçado de uma parábola no plano cartesiano. O traçado da parábola é um interpretante produzido pelo aluno que pode associá-lo a um novo signo - o signo gráfico - em um plano cartesiano que descreve tal trajeto. Diante desse novo signo, o aluno pode relacioná-lo com uma função polinomial do segundo grau e produzir o seguinte interpretante: $f(x)=a x^{2}+b x+c$. Esse interpretante consiste em um novo signo quando o intérprete realiza cálculos para determinar os parâmetros da função polinomial do segundo grau. As regras e relações utilizadas para a obtenção dos cálculos correspondem ao interpretante produzido a partir do signo expressão algébrica. Com os resultados, o intérprete tem o signo algébrico que descreve o trajeto da bola de basquete, que é um novo signo. Ao se aventurar a identificar o ponto de máximo da função por meio de cálculos para determinar o ponto do vértice, o intérprete gera novos interpretantes que, posteriormente, serão signos do objeto função polinomial do segundo grau, em um ciclo ad infinitum.

O que podemos conjecturar é que a produção de um signo por alguém (intérprete) é permeada pelo uso de recursos diversos, seja um gesto, um esquema, um diagrama, softwares, uso de materiais manipulativos.

Para Mavers (2004), os recursos que foram escolhidos e trabalhados para produzir signos são caracterizados como recursos semióticos. Segundo o autor, por meio da funcionalidade dos recursos semióticos é possível evidenciar os significados dos signos individuais. Por exemplo, para produzir signos gráficos, os alunos podem lançar mão de diversos recursos semióticos de acordo com seus interesses e motivações em um contexto social específico. 
Ao abordar o estudo de antiderivada por meio de recursos gráficos por duas professoras de Matemática, Thomas, Yoon e Dreyfus (2009, p. 545) evidenciaram que "a versatilidade de mudar os recursos semióticos não apenas reduz a carga cognitiva, mas também traz benefícios em termos de reconhecimentos para o recurso". Isso porque as professoras fizeram uso de um recurso semiótico - espaço virtual - do qual não tinham familiaridade e identificaram sua funcionalidade sem a necessidade de prévia explicação. Além disso, ao trabalharem juntas com a representação gráfica da antiderivada, as professoras fizeram uso de gestos para explicar o que haviam construído destacando que este recurso semiótico tem "uma capacidade dinâmica quando comparada com representações gráficas estáticas, facilitando o entendimento sob uma perspectiva global" (THOMAS; YOON; DREYFUS, 2009, p. 545).

Neste sentido, corroboramos com van Leeuwen (2005) que esclarece que a ideia de um recurso semiótico enfatiza o potencial semiótico de um signo ou sistema de signos. Manipular a representação gráfica por meio de um software analisando a variação dos coeficientes potencializa o signo gráfico permitindo visualização do comportamento da função.

Uso de recursos semióticos distintos está presente no desenvolvimento de atividades de modelagem matemática. Em pesquisa para evidenciar o raciocínio cúbico de alunos ao desenvolver uma atividade de modelagem, Yoon e Miskell (2016, p. 90) concluíram que a eficácia dos recursos semióticos "depende se eles permitem que os alunos visualizem, testem e examinem a existência de abordagens matemáticas incorretas à medida que avançam em torno do ciclo de modelagem". Em nossa pesquisa, todavia, nosso foco está no uso de tecnologias para o desenvolvimento de uma atividade de modelagem matemática.

\section{Aspectos metodológicos}

Para evidenciarmos como a tecnologia se configura como recurso semiótico no desenvolvimento de uma atividade de modelagem matemática foi desenvolvida uma atividade com 15 alunos de uma turma do nono ano do Ensino Fundamental de uma escola privada situada no norte do Paraná. O professor dos alunos, um dos autores deste artigo, tem formação em Matemática e Química e orientou o desenvolvimento da atividade. Neste artigo é referenciado como P. 
Considerando o interesse do professor em aliar conteúdos trabalhados na disciplina de Matemática com aqueles próprios das Ciências, em especial, da Química, decidiu desenvolver com os alunos uma atividade experimental investigativa. Alinhado à caracterização de atividade experimental investigativa, em que os alunos se mobilizam "à procura de uma metodologia para a sua resolução" (SUART; MARCONDES, 2009, p. 55), o desenvolvimento da atividade ocorreu parte em encontros extraclasse dos alunos com o professor e parte em aulas de Matemática nos horários regulares. Os encontros extraclasse ocorreram na própria escola, no horário de contraturno dos alunos.

De certo modo, essa abordagem seguiu a possibilidade de combinação sugerida por Blum e Niss (1991) para a inclusão da Modelagem Matemática no currículo da disciplina de Matemática. Para Almeida, Silva e Vertuan (2012), a partir dessa possibilidade:

A flexibilidade em relação ao programa escolar e a disponibilidade do professor que pode emergir da introdução da modelagem nas aulas regulares não representam mais uma "dificuldade" ao mesmo tempo em que atividades de Modelagem Matemática passam a integrar as aulas regulares de Matemática (ALMEIDA; SILVA; VERTUAN, 2012, p. 22).

A atividade experimental investigativa está relacionada à velocidade do ar liberado pelo Canhão de vórtex, que é um equipamento que dispara anéis de ar ou outro gás qualquer, também conhecido como bazuca de ar. O interesse dos alunos em estudar tal situação se voltou para a relação entre o diâmetro do orifício e a velocidade de saída do ar.

O desenvolvimento da atividade foi realizado com os alunos reunidos em quatro grupos (G1, G2, G3 e G4) e em cinco momentos diferentes, conforme apresentado no Quadro 1.

\begin{tabular}{|c|c|}
\hline Momentos de desenvolvimento & Abordagem(ns) realizada(s) \\
\hline $\begin{array}{l}1 \text { - extraclasse no laboratório da } \\
\text { escola. }\end{array}$ & $\begin{array}{l}\text { Apresentação da situação a ser investigada a partir do contato com } \\
\text { um vídeo }{ }^{8} \text { que mostra a construção e o funcionamento de um } \\
\text { Canhão de vórtex utilizando materiais de fácil acesso. } \\
\text { Discussão na qual os alunos refletiram sobre a situação a ser } \\
\text { investigada e buscaram relacionar as formas de se simular a } \\
\text { velocidade com aqual o ar era liberado do canhão. }\end{array}$ \\
\hline $\begin{array}{l}2 \text { - extraclasse na quadra } \\
\text { poliesportiva da escola. }\end{array}$ & $\begin{array}{l}\text { Cada grupo construiu e manipulou um canhão com diferentes } \\
\text { diâmetros de saída de ar }-3 \mathrm{~cm}(\mathrm{G} 1), 6 \mathrm{~cm}(\mathrm{G} 2), 9 \mathrm{~cm}(\mathrm{G} 3) \text { e } 12 \\
\mathrm{~cm}(\mathrm{G} 4) \text {. } \\
\text { Desenvolvimento da atividade experimental investigativa com } \\
\text { coleta de dados empíricos por meio da filmagem da atividade. }\end{array}$ \\
\hline
\end{tabular}

${ }^{8}$ Disponível em https://www.youtube.com/watch?v=Qp7UgQ4TBkg. Acesso em: 16 nov. 2018. 


\begin{tabular}{|l|l|}
\hline $\begin{array}{l}3 \text { - aula regular da disciplina de } \\
\text { Matemática no laboratório de } \\
\text { informática. }\end{array}$ & $\begin{array}{l}\text { Análise e interpretação dos dados obtidos experimentalmente com } \\
\text { o auxílio do software Tracker. }\end{array}$ \\
\hline $\begin{array}{l}4 \text { - aula regular da disciplina de } \\
\text { Matemática no laboratório de } \\
\text { informática. }\end{array}$ & $\begin{array}{l}\text { Dedução do modelo matemático e obtenção de uma solução para } \\
\text { o problema. }\end{array}$ \\
\hline $\begin{array}{l}5 \text { - extraclasse na quadra } \\
\text { poliesportiva da escola e no } \\
\text { laboratório de informática. }\end{array}$ & $\begin{array}{l}\text { Análise e validação do resultado experimentalmente a partir da } \\
\text { construção de um novo canhão, que atendia às especificações } \\
\text { obtidas a partir do modelo matemático. }\end{array}$ \\
\hline
\end{tabular}

Quadro 1: Momentos de desenvolvimento da atividade

Fonte: Dos autores

Para a nossa análise fizemos uso, principalmente, da transcrição de gravações em áudio e vídeo do desenvolvimento da atividade nos diferentes momentos, realizadas mediante autorização assinada pelos pais ou responsáveis. No decorrer da nossa descrição utilizamos a letra A e um número para nos referirmos a cada um dos 15 alunos da turma (A1, A2, A3, .., A15). Esses alunos estavam dispostos nos quatro grupos, assim constituídos: G1 - A1, A2, A3 e A4; G2 - A5, A6, A7 e A8; G3 - A9, A10, A11 e A12; G4 - A13, A14 e A15.

Do ponto de vista metodológico, realizamos uma pesquisa de abordagem qualitativa. Nessa abordagem, segundo Bogdan e Biklen (1994, p. 51), os investigadores "estabelecem estratégias e procedimentos que lhes permitam tomar em consideração as experiências do ponto de vista do informador".

\section{Descrição e análise da atividade de modelagem matemática Canhão de vórtex}

Nesta seção apresentamos uma descrição e analisamos cada momento do desenvolvimento da atividade de modelagem com o intuito de inferir sobre como a tecnologia se configura como recurso semiótico.

\subsection{Momento 1: evidenciando uma situação-problema}

Para iniciar o desenvolvimento da atividade, foi solicitado aos alunos que movimentassem, utilizando somente o ar, um copo plástico que se encontrava sobre a bancada do laboratório do lado oposto ao qual estavam. Para tanto, os grupos buscaram derrubar o copo utilizando sopros e leques, sem sucesso.

Observando a dificuldade apresentada, o professor sugeriu o uso de um instrumento construído com um funil e um pedaço de luva de látex colado na extremidade maior. Ao fazer uso desse instrumento, os alunos verificaram que, ao puxar e soltar a

${ }^{9}$ Disponível em https://physlets.org/tracker/. Acesso em: 16 nov. 2018. 
membrana formada pela luva de látex, o ar era expelido do sistema com uma velocidade considerável, movimentando o copo. De modo a corroborar com tal abordagem, foi apresentado um vídeo mostrando a construção de um Canhão de vórtex, utilizando um balde, uma folha de acetato e fita adesiva.

A partir do vídeo foi possível promover uma discussão sobre o fenômeno observado, conforme transcrição das falas de um aluno e do professor ao discorrerem sobre o princípio por trás do funcionamento do canhão:

P: Como vocês explicam o experimento que estava no vídeo?

A6: A saída do ar era menor que o espaço onde o ar estava. Quando dava o impulso, o ar saía com alta velocidade.

P: Como assim?

A6: A saída era menor para o tanto de ar que tinha dentro. Quando saía, ele saía todo de uma vez e ele ia com pressão.

O vídeo apresentado para os alunos se configurou como um recurso semiótico, pois possibilitou que examinassem os princípios envolvidos no Canhão de vórtex, além de possibilitar a A6 a produção de um signo interpretante no que diz respeito à velocidade de saída do ar.Isso porque o signo produzido por A6 "não é qualquer signo, mas um signo que interpreta o fundamento" (SANTAELLA, 2009, p. 43).

Com a produção dos signos interpretantes de A6 com relação ao fenômeno envolvido no canhão, ao longo da discussão, de certa forma, convenceu os demais alunos que pareciam concordar ao assinalar positivamente por meio de gestos com a cabeça o que estava sendo abordado. Isso denota que os alunos compreenderam o fenômeno observado no que consiste ao fato da liberação do ar a partir de dimensões menores do que aquela da parte superior do canhão.

De posse dessas análises e evidências do fenômeno, o professor propôs aos alunos a construção de um canhão no qual o ar era liberado com a maior velocidade. Considerando o que haviam observado no vídeo, bem como da manipulação do artefato construído com o funil e a luva de látex que estava no laboratório, cada grupo destacou fatores que interfeririam na velocidade de saída do ar, conforme transcrição de falas compartilhadas com toda a turma:

P: E se por acaso a gente quiser alterar a velocidade do canhão? O que podemos mudar?

A5: Para alterar a velocidade que o ar sai, podemos alterar o tamanho da saída ou a pressão dentro do canhão.

P: Como que funciona essa alteração na saída?

A6: Se a saída for menor, sai com mais velocidade. Se for maior, sai com menos.

P: E para vocês? O que alteraria a velocidade? [se voltando para o G1]

A1: O tamanho da saída do canhão, a força que você coloca e o tamanho do recipiente. 
P: Vocês também colocaram o tamanho da saída. Como isso varia?

A2: Se a saída for menor, o ar sai com mais pressão.

P: E o que acontece com a velocidade?

A1: Fica maior.

P: E vocês? [solicitando as considerações de G3]

A9: Para mudar a velocidade do ar, sem mudar o impulso, podemos mudar o tamanho do buraco.

A10: Deixar maior.

P: E se ficar maior, o ar vai sair mais rápido?

A9: Se deixar maior, vai dar o impulso lá, sai com menos velocidade. Agora se colocar menor e colocar impulso, a pressão faz com que saia com maior velocidade.

O que podemos evidenciar é que os grupos mencionaram fatores como dimensão do canhão, força do impacto sobre a membrana e diâmetro do orifício de saída do ar. No entanto, os grupos mencionaram que o tamanho do orifício de saída do ar interferiria na velocidade. Com isso, optou-se por considerar uma dimensão específica para o canhão e investigar a velocidade do ar de acordo com o diâmetro do orifício de saída. Para isso, os grupos tomaram como hipótese que quanto menor fosse o orifício de saída de ar do canhão, maior seria a velocidade atingida pelo ar. Essa hipótese, todavia, estava associada às percepções e conhecimentos dos alunos sobre fenômenos que relacionam pressão do ar em um sistema e que poderia ser considerada ou descartada por meio do desenvolvimento de uma atividade experimental investigativa. Em uma análise semiótica, a percepção consiste no "processo mental que possibilita e amplia arelação do indivíduo com seu entorno" (NETTO; PERASSI; FIALHO, 2013, p. 250), ou seja, os alunos articulam conhecimentos abordados em outros contextos de sua formação com aquele que estava sendo solicitado no desenvolvimento da atividade. Além disso, "a promoção de atividades investigativas com enfoque experimental possibilita a integração de objetivos conceituais e epistêmicos" (SILVA; TRIVELATO, 2017, p. 150).

\subsection{Momento 2: coletando dados empíricos}

Cada grupo ficou responsável pela construção de um canhão: G1 construiu o canhão com 3 cm de saída; G2 o de 6 cm; G3 o de 9 cm e G4 o de 12 cm. Para a construção dos canhões foram utilizados baldes idênticos, nos quais foram feitos orifícios em sua parte inferior. Com o auxílio de compasso e papel cartão, os grupos fizeram representações circulares de diferentes diâmetros (Figura 1) para a determinação do orifício de saída do canhão. As saídas de ar foram feitas utilizando uma faca aquecida, facilitando o corte do balde. Uma folha de acetato foi afixada na parte superior do balde (Figura 2), constituindo uma membrana na qual seria aplicada a força. 


\section{$R_{\text {ebeCEM }}$}

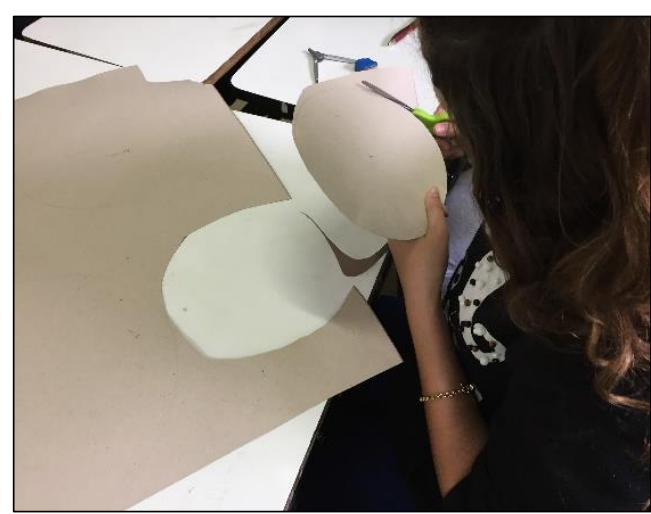

Figura 1: A11 confeccionando o molde de $9 \mathrm{~cm}$ Fonte: Arquivo do professor
Revista Brasileira de Educação em

Ciências e Educação Matemática

ISSN 2594-9179

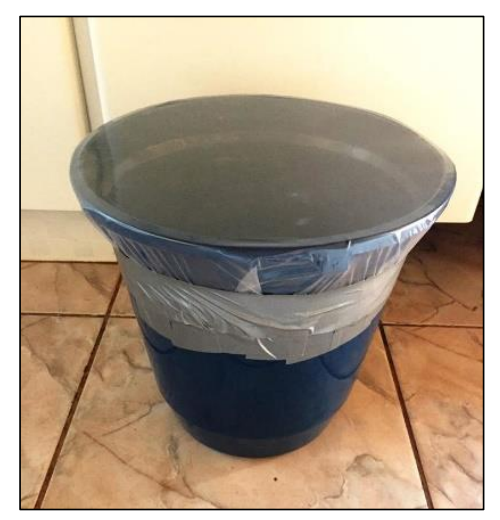

Figura 2: Membrana na parte superior do canhão Fonte: Arquivo do professor

Nesta atividade, o balde passou a ser um signo interpretado como um Canhão de vórtex, pois este é o representámen do objeto "Canhão de vórtex" para o fenômeno em estudo pelos alunos. Este signo "está enraizado num vastíssimo mundo de relações com outros signos" (SANTAELLA, 2009, p. 45) que foram produzidos pelos alunos para sua constituição. O objeto desse signo assim constituído é a velocidade de saída do ar.

Com a construção do canhão, enquanto um signo que pode proporcionar uma relação com o objeto matemático velocidade do ar, uma indagação se constituiu: como "visualizar" a saída do ar? O professor já havia previsto essa questão e orientou os alunos a utilizar bastões de fumaça colorida. Essa associação foi realizada, pois no vídeo que os alunos entraram em contato no momento 1, foi utilizado gelo seco. A fumaça colorida, assim como o gelo seco, permite evidenciar o trajeto do ar ao deixar o canhão e o acompanhamento da trajetória dos anéis de fumaça. A fumaça colorida, neste momento, se constitui como um recurso semiótico que permite a visualização, antes impossibilitada, da saída do ar e do trajeto dos anéis de fumaça. Neste caso podemos ponderar "a versatilidade de mudar os recursos semióticos [...] em termos de reconhecimentos para o recurso" (THOMAS; YOON; DREYFUS, 2009, p. 545).

Esse momento da atividade foi gravado em vídeo na quadra poliesportiva da escola. Para isso, o professor em conjunto com os alunos determiram locais fixos, tanto para o tripé com a filmadora quanto para o aluno manusear o canhão. Um representante de cada grupo manuseou o canhão que confeccionou, conforme mostra a Figura 3. 


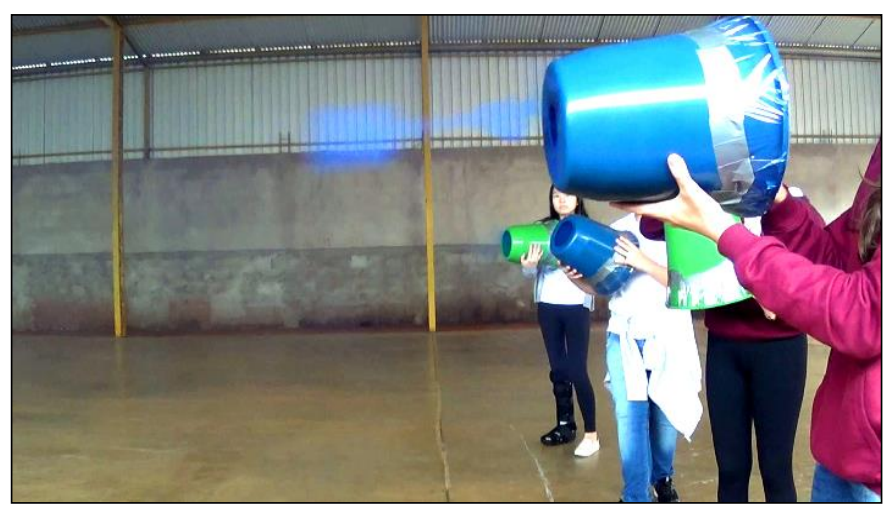

Figura 3: A5 manuseando o canhão com $6 \mathrm{~cm}$ de diâmetro Fonte: Arquivo do professor

No desenvolvimento da atividade, os alunos observaram que o canhão com saída de menor diâmetro $(3 \mathrm{~cm})$ não aparentava ser aquele com a maior velocidade, conforme falas dos mesmos no decorrer da atividade experimental, como segue na transcrição:
P: Gente, o que vocês puderam perceber?
A7: Eu acho que o da A5 [canhão de saída com $6 \mathrm{~cm}$ ] e o do A2 [canhão de saída com $3 \mathrm{~cm}$ ] foram os mais rápidos.
A14: O meu [canhão de saída com $12 \mathrm{~cm}$ ] nem saiu direito...
P: Qual vocês acharam que foi o mais rápido?
A1: Eu acho que foi o de 6 centímetros.
P: Mas vocês não falaram que quanto menor fosse o buraco mais rápido sairia o ar?
A6: Sim, mas acho que se for muito pequeno, o ar não consegue sair tudo de uma vez. Ele bate no fundo do balde.
P: Como assim?
A9: É só pensar que vai ter muito ar querendo sair por um espaço pequeno. Igual se tiver muita gente querendo passar por um espaço minúsculo.
P: Desenvolve mais, A9.
A9: Igual acontece no corredor [da escola, que possui apenas uma porta para o acesso à quadra]. Se tiver muita gente querendo passar ao mesmo tempo... Não vão conseguir.

Embora os alunos, no início do desenvolvimento da atividade, estivessem convictos de que a velocidade do ar seria maior para o canhão com menor orifício de saída, foi por meio da atividade experimental que tal hipótese foi refutada.Isso porque neste tipo de atividade, os alunos desenvolvem a capacidade "de elaborar hipóteses, testálas e discuti-las, aprendendo sobre os fenômenos estudados e os conceitos que os explicam, alcançando os objetivos de uma aula experimental" (SUART; MARCONDES, 2009, p. 51).

Além disso, o uso de gravação em vídeo é um recurso tecnológico que possibilita visualizar o mesmo fenômeno várias vezes, possibilitando a realização de sua análise que exige "retrocessos frequentes, reverificação e nova avaliação porque as mudanças acontecem rapidamente" (MAVERS, 2004, p. 84). 


\subsection{Momento 3: analisando os dados em busca de uma interpretação matemática}

A análise dos vídeos foi feita com o auxílio do softwareTracker, no laboratório de informática da escola, em aula regular da disciplina de Matemática. O professor apresentou a funcionalidade desse software para os alunos, bem como as ferramentas necessárias para se realizar a videoanálise, conforme transcrição:

P: Façam o seguinte, dentro daquela pasta Experimentos eu deixei o vídeo do experimento que cada grupo fez. Eu quero que vocês abram o vídeo do seu grupo.

[...]

P: A13, clica e arrasta o vídeo.

A13: Assim?

P: Isso.

P: Todo mundo clica no triângulo verde e vê se o vídeo tá rodando.

A11: Professor, ele tá em câmera lenta, é assim mesmo?

P: Sim. Como o programa serve para analisar cada frame, o vídeo mostra assim mesmo.

P: Agora vocês vão na parte que tá escrito "Track", lá na barra de cima. Depois em "axes" e seleciona a parte que tá escrito "Visible". O que aconteceu?

A2: Apareceram umas retas.

P: Sim. Essas retas servirão para a gente analisar o deslocamento do ar.

P: Antes de tudo, prestem atenção. Vocês irão encontrar o quadro que a fumaça começa a sair do canhão. Para isso voltem o vídeo, clicando naquele símbolo do lado do triângulo verde...

P: Vão clicando no símbolo que tá escrito, deixa eu ver... "Stepforward", do lado do número 1. E cliquem até o momento que o ar vai começar a sair do canhão.

P: Quando a fumaça começar a sair, é só voltar um quadro. Esse vai ser o nosso instante zero.

$[\ldots]$

P: Então agora, vocês vão exatamente no meio dos dois eixos e arrastem para que eles fiquem exatamente no meio da saída do canhão.

A2: Não entendi.

P: É só arrastar para deixar as retas no meio da saída... Assim. [manipulando o mouse e apresentando a A2]

P: Agora, vocês precisam ajustar a inclinação dos eixos, para que essa reta horizontal fique exatamente no caminho da fumaça. Cliquem para avançar o vídeo e vejam o sentido do movimento.

P: Agora arrastem a reta para que ela fique em cima da fumaça.

P: Deixa eu ver... Ainda não ficou certo.

A7: Precisa ficar mais para baixo?

P: Sim, olha... No começo ainda tá certo, mas depois a reta fica errada.

A7: Assim? [ajustando os eixos]

P: Isso. Melhorou.

O software possibilita a análise de corpos em movimento a partir de vídeos ou de conjuntos de fotos sequenciais. Como o software separa o vídeo por quadros, para cada quadro é possível estabelecer um "ponto de massa" que corresponde à localização do objeto a ser analisado. Os alunos, na aula regular, necessitaram de auxílio do professor para fazer a análise e os signos interpretantes produzidos seguiram aqueles enunciados pelo professor. Um aspecto que podemos considerar é de que caso os alunos tivessem um 
tempo maior para o tratamento dos dados, outros signospoderiam ser produzidos. Mendes e Oliveira (2018) alegam em seu estudo que o fato de os alunos não terem familiaridade com o software de videoanálise e a limitação do tempopodem influenciar nas fases de inteiração e dematematização. Mesmo assim, os alunos procuram entender o que o professor está orientando e fazem afirmações e questionamentos com o intuito de evidenciar se as instruções que receberam foram compreendidas. Segundo Almeida, Silva e Ramos (2018, p. 5), "a comunicação cria umvasto sistema semiótico que requer a realização de interpretações para possibilitar aconstrução de conhecimentos”.

A localização dos "pontos de massa" permite que seja estabelecida uma relação entre o deslocamento de um objeto em função do tempo. Assim, o Tracker, nesta atividade, é um recurso semiótico que permite aos alunos acompanhar o deslocamento do ar com base em um sistema de eixos ortogonais, produzindo dados para serem interpretados matematicamente. Esse recurso semiótico tem fundamental importância para que se possa analisar a relação entre as variáveis estudadas, pois, a partir do registro em vídeo, o software permite capturar nuances do movimento, que não seriam possíveis sem esse recurso.

O que podemos evidenciar na transcrição supracitada é que os grupos foram orientados a manipular o sistema de eixos de modo com que o eixo das abscissas coincidisse com o deslocamento do ar (Figuras 4 e 5).

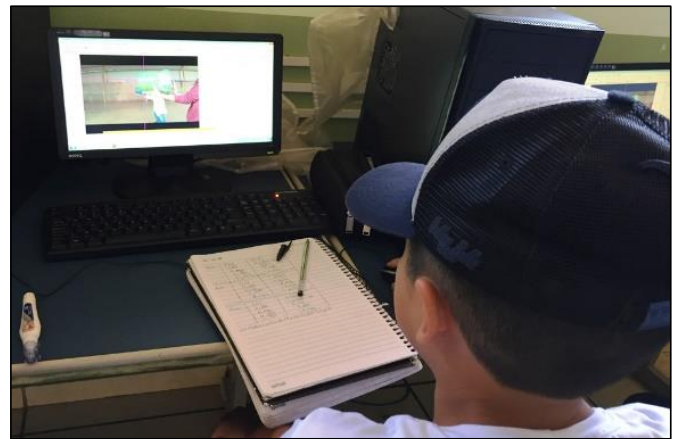

Figura 4: A6 realizando a análise no Tracker Fonte: Arquivo do professor

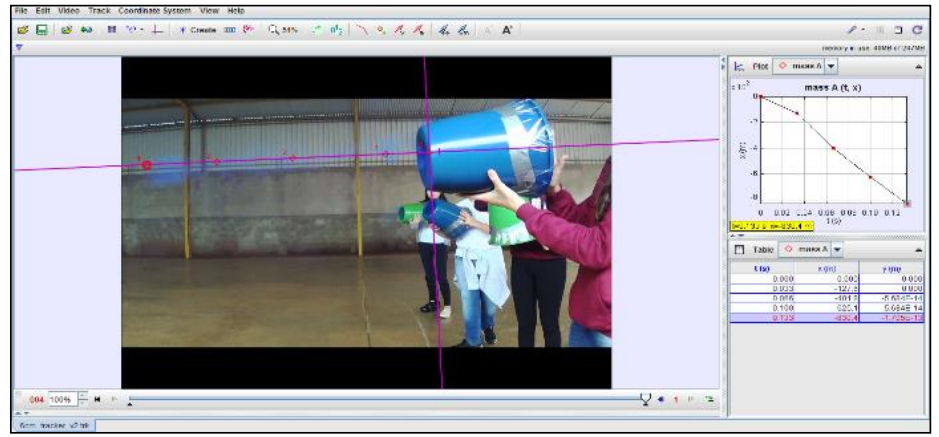

Figura 5: Captura dde tela da análise realizada no Tracker para o canhão com $6 \mathrm{~cm}$ de diâmetro

Fonte: Arquivo do professor

Ao realizar os procedimentos explicados pelo professor, os alunos produziram os dados com relação à distância e o tempo assim que o jato de ar representado pela fumaça colorida saía do orifício até praticamente se dispersar para o ambiente. Com esses dados, foi possível contruiro Quadro 2. 
ISSN 2594-9179

\begin{tabular}{|c|c|c|}
\hline Diâmetro do orifício (cm) & Tempo (s) & Distância (m) \\
\hline \multirow{4}{*}{3} & 0 & 0 \\
\cline { 2 - 3 } & 0,033 & 0,344 \\
\cline { 2 - 3 } & 0,066 & 0,624 \\
\cline { 2 - 3 } & 0,1 & 0,859 \\
\hline \multirow{4}{*}{6} & 0 & 0 \\
\cline { 2 - 3 } & 0,033 & 0,138 \\
\cline { 2 - 3 } & 0,066 & 0,541 \\
\cline { 2 - 3 } & 0,1 & 0,885 \\
\hline \multirow{4}{*}{9} & 0 & 0 \\
\cline { 2 - 3 } & 0,033 & 0,166 \\
\cline { 2 - 3 } & 0,066 & 0,403 \\
\cline { 2 - 3 } & 0,1 & 0,66 \\
\hline \multirow{4}{*}{12} & 0 & 0,118 \\
\hline & 0,033 & 0,224 \\
\hline
\end{tabular}

Quadro 2: Dados coletados com o auxílio da videoanálise

Fonte: Relatório dos alunos

Outra interpretação matemática, para além do signo tabular, se fez necessária por parte dos alunos, que estavam acostumados em outras atividades já desenvolvidas em sala de aula, representar gráficos e expressões algébricas. O que podemos conjecturar com isso é que a tabela consiste em um signo, pois é "capaz de dar origem a outros signos" (PEIRCE, 1972, p. 27).

\subsection{Momento 4: deduzindo um modelo matemático e obtendo uma solução para o problema}

De posse dos dados coletados via análises realizadas no Tracker, os alunos auxiliados pelo professor determinaram a velocidade média para cada canhão, considerando a variação da distância em um espaço de um segundo, conforme transcrição:

P: [...] Se a gente tem a distância e tem o tempo o que podemos calcular?

A9: O quanto ele andou.

P: Tá, mas que informação podemos obter com distância e tempo? Volta lá na Física A6!

A6: Velocidade?

P: Como que calcula velocidade?

A6: Distância sobre tempo.

P: Isso. Podemos calcular a velocidade média de cada canhão.

P: Vamos manter um padrão: eu quero que vocês peguem a quarta distância e subtraiam pela primeira distância? Da coluna $x$.

$[\ldots]$

P: Como estamos fazendo nos primeiros quatro quadros, vamos determinar a velocidade em um intervalo de 0,1 segundo. Então dividam o 0,859 por 0,1 .

P: Ou melhor, nem precisa fazer conta... Qual vai ser o valor da velocidade?

A6: 8,59.

P: Esse valor é o que?

A6: Velocidade.

P: E qual é a unidade?

P: A distância está em que unidade? 
A6: Metros?

P: Sim. E o tempo?

A2: O tempo em segundos. Então vai ser metros por segundo.

Com as orientações do professor, os alunos passaram a abordar a situaçãoproblema considerando a velocidade média do ar para cada canhão. O que aconteceu foi que para continuar investigando e produzindo novos signos para a situação em estudo, professor e alunos buscaram realizar uma simplificação. Para Bleiler-Baxter e Barlow (2016, p. 57), a simplificação consiste em um processo "crítico para que os alunos possam produtivamente avançar no mapeamento de relações matemáticas na situação".

Para dar encaminhamento à abordagem, os alunos inseriram uma coluna no Quadro 2 considerando as informações obtidas com o cálculo das médias das velocidades, conforme apresentado no Quadro 3.

\begin{tabular}{|c|c|c|c|}
\hline $\begin{array}{l}\text { Diâmetro do orifício } \\
(\mathrm{cm})\end{array}$ & Tempo (s) & Distância (m) & $\begin{array}{c}\text { Velocidade média } \\
(\mathrm{m} / \mathrm{s})\end{array}$ \\
\hline \multirow[t]{4}{*}{3} & 0 & 0 & \multirow[t]{4}{*}{8,59} \\
\hline & 0,033 & 0,344 & \\
\hline & 0,066 & 0,624 & \\
\hline & 0,1 & 0,859 & \\
\hline \multirow[t]{4}{*}{6} & 0 & 0 & \multirow[t]{4}{*}{8,85} \\
\hline & 0,033 & 0,138 & \\
\hline & 0,066 & 0,541 & \\
\hline & 0,1 & 0,885 & \\
\hline \multirow[t]{4}{*}{9} & 0 & 0 & \multirow[t]{4}{*}{6,6} \\
\hline & 0,033 & 0,166 & \\
\hline & 0,066 & 0,403 & \\
\hline & 0,1 & 0,66 & \\
\hline \multirow[t]{4}{*}{12} & 0 & 0 & \multirow[t]{4}{*}{4,1} \\
\hline & 0,033 & 0,118 & \\
\hline & 0,066 & 0,224 & \\
\hline & 0,1 & 0,41 & \\
\hline
\end{tabular}

Quadro 3: Velocidades médias obtidas em cada canhão

Fonte: Relatório dos alunos

Os valores das velocidades médias foram, então, representados em uma planilha do Microsoft Excel, na qual os alunos construíram um gráfico relacionando a velocidade média de cada canhão e o diâmetro do orifício (Figura 6) e ajustaram os dados a uma curva, cuja representação algébrica é dada pory $=-0,0767 x^{2}+0,626 x+7,515$, em que $y$ corresponde à velocidade em função do diâmetro $x$ de saída do ar (Figura 7). 


\section{$R_{\text {eBECEM }}$}

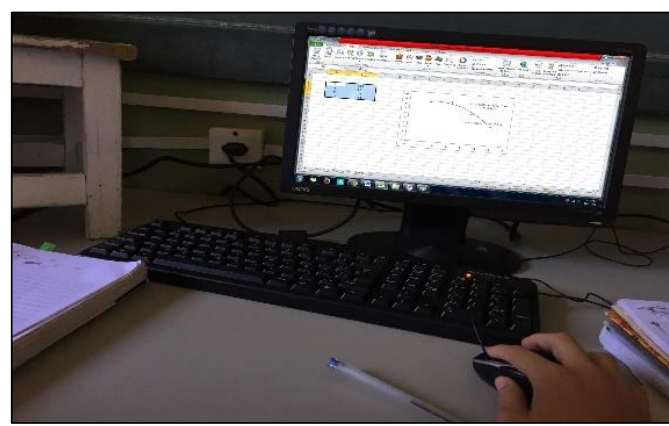

Figura 6: A9 realziando as análises no Excel Fonte: Arquivo do professor
Revista Brasileira de Educação em

Ciências e Educação Matemática

ISSN 2594-9179

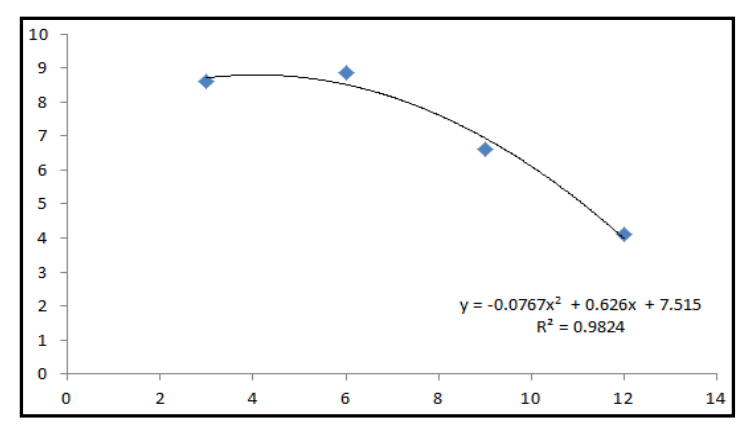

Figura 7: Gráfico obtido pelo Microsoft Excel Fonte: Registro dos alunos

A função polinomial do segundo grau é um objeto matemático que faz parte da matriz curricular do nono ano do Ensino Fundamental e já foi estudado pelos alunos em aulas anteriores ao desenvolvimento da atividade de modelagem matemática. Ao produzirem a representação gráfica da velocidade média do ar em função do diâmetro do orifício do canhão, bem como obter o signo algébrico dessa representação, de certo modo, os alunos entraram em contato com signos matemáticos que representam sob certa forma e capacidade uma função polinomialdo segundo grau que pode representar o fenômeno em estudo. Defronte dos signos produzidos com o auxílio do Microsoft Excel e considerando os encaminhamentos realizados pelo professor, os alunos produziram novos signos para o objeto função polinomial do segundo grau, conforme transcrição:

P: [...] Agora que a gente obteve a função, o que vocês podem perceber quanto à curva?

A1: O valor do [coeficiente] $a$ é negativo. A curva é para baixo.

P: Sim, a concavidade é para baixo. Todos conseguiram?

P: Vejam os pontos das velocidades e me digam o que acontece.

A3: Mas os pontos não estão em cima da curva.

P: Sim. Isso pode acontecer mesmo. Como estamos trabalhando com uma situação real, pode ser mais difícil de prever. Estamos simplificando.

A3: Como assim?

P: Por exemplo, todos deveriam bater no canhão com exatamente a mesma força. Mas não é o que aconteceu... Não tinha como a gente controlar isso. Qualquer diferença acaba interferindo no experimento. Mas não precisamos considerar isso, porque a característica da função ainda está presente.

A3: Ah sim...

P: Gente, agora observem o gráfico. Os experimentos que nós fizemos tiveram a velocidade máxima?

A6: Parece que não.

P: E como que você viu isso?

A6: Se olhar entre o 3 e o 6, dá para ver que a curva ainda sobe um pouco.

P: Isso é porque não foi o ponto de máximo mesmo. Mas a gente consegue calcular esse valor, igual fizemos nas aulas, lembram?

A2: Sim. Tinha uma fórmula...

[...]

$\mathrm{P}:$ Isso! O que a gente encontra através dessa fórmula?

A6: O valor de $x$ que a função é o maior.

P: Sim, é o valor para $x$ no qual obtemos o ponto de máximo absoluto da função. Assim podemos encontrar para que diâmetro a velocidade será a máxima. 
P: Vamos ver... Qual é o valor do coeficiente $b$ da função?

A2: 0,626 .

P: E o valor de $a$ ?

A2: 0,0767 .

[...]

A6: Vai dar 4,08?

[...]

A1: Deu isso.

P: O que isso significa então, gente?

A6: Que o canhão de 4 centímetros é o mais rápido.

P: Em teoria sim. Precisamos testar e ver se está certo ou não. Iremos fazer isso depois e ver se a velocidade será maior que a dos outros mesmo.

O signo algébrico possibilita aos alunos considerarem informações relativas aos coeficientes e o comportamento gráfico da função quando o A1 afirmou " $a$ é negativo. A curva é para baixo". Ao mesmo tempo em que produziu um signo interpretante que relacionava o comportamento da função de acordo com o coefiente nela presente, por meio do uso do Microsoft Excel, o aluno podia visualizar tal afirmação com os registros produzidos e apresentados na tela do computador. O computador, neste caso, consiste em um recurso que possibilitou a visualização dos signos produzidos para o objeto matemático função polinomial do segundo grau. Isso, segundo van Leeuwen (2005), enfatiza o potencial semiótico do signo gráfico e permite analisar o comportamento da função.

Ainda, por meio do signo algébrico, o professor solicitou aos alunos que calculassem o ponto de máximo da função polinomial do segundo grau. Para isso, precisaram identicar os coeficientes $a$ e $b$, relembrar que "tinha uma fórmula", como mencionado por A2 para então calcularem "O valor de $x$ que a função é o maior" conforme complementou A6. Os signos interpretantes produzidos por A2 e A6 complementaram a abordagem iniciada por A3 e conduziram os alunos a fazerem uso da expressão $x_{v}=\frac{-b}{2 a}$ e determinarem o ponto de máximo, ou seja, o ponto do vértice da parábola, identificando que para um valor de diâmetro igual a 4,08 cm, a velocidade do ar liberado pelo canhão émáxima.

Os alunos ainda aceitaram o convite do professor que considerou: "Precisamos testar e ver se está certo ou não" e realizaram uma nova atividade experimental com vistas a validar a solução encontrada, buscando julgar "a consistência dos diversos dados obtidos, a validade de um determinado modelo teórico para explicá-los" (SILVA; TRIVELATO, 2017, p. 150). 


\subsection{Momento 5: validando a solução experimentalmente}

Para validar a solução obtida matematicamente foi construído um novo canhão com diâmetro de cerca de 4,08 cm. Os experimentos e as análises ocorreram em conformidade com a atividade experimental investigativa realizada anteriormente. Para a determinação da velocidade os alunos recorreram novamente ao Tracker, conforme indicado na Figura 8.

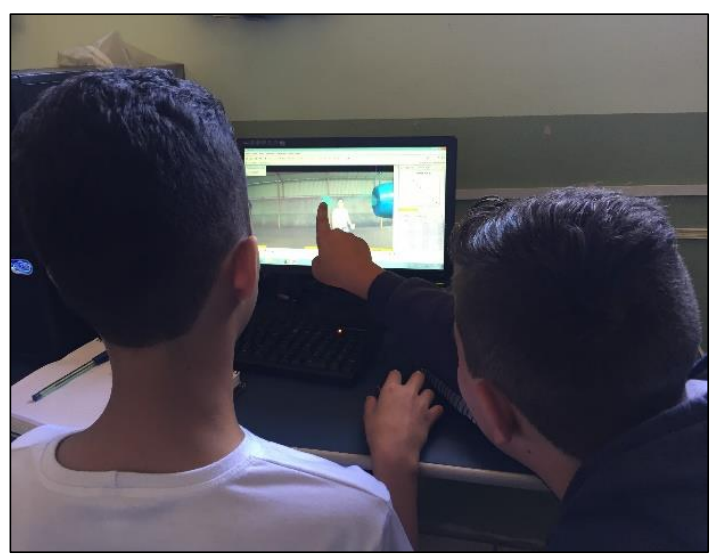

Figura 8: Alunos realizando videoanálise do canhão de 4,08 cm de diâmetro Fonte: Arquivo do professor

Neste "novo" desenvolvimento da atividade, os alunos já estavam familiarizados com o software Tracker e apresentaram maior autonomia para a determinação dos valores de localização em função do tempo da fumaça colorida. Segundo Manechine e Caldeira (2006, p. 3), "na medida em que o educando vai se familiarizando eapreendendo determinados signos universais, esses vão se tornando objetos referenciais paraconexão, relação e apropriação de novos signos".

A partir dos dados coletados por meio do Tracker para analisar a distância em função do tempo dos anéis de fumaça (Quadro 4), os alunos evidenciaram que a velocidade média do ar do canhão cujo diâmetro de saída mede 4,08 cm é de 9,41 m/s.

\begin{tabular}{|c|c|}
\hline Tempo (s) & Distância (m) \\
\hline 0 & 0 \\
\hline 0,033 & 0,226 \\
\hline 0,066 & 0,592 \\
\hline 0,1 & 0,941 \\
\hline
\end{tabular}

Quadro 4: Dados do canhão com 4,08 cm

Fonte: Relatório dos alunos

O valor da velocidade média determinada para o canhão com 4,08 cm de diâmetro de saída para o ar é maior do que a velocidade de $8,85 \mathrm{~m} / \mathrm{s}$ do canhão de saída com $6 \mathrm{~cm}$ de diâmetro. A discussão acerca da obtenção da velocidade segue na transcrição: 
P: Que valor vocês encontraram?

A6: 9,41 .

P: Todos acharam esse valor?

A1: O nosso deu quase isso.

P: Tá... A velocidade foi maior que a dos outros canhões?

P: Só para lembrar, o canhão de 3 centímetros deu 8,5 e o canhão de 6 deu 8,8. A9: Sim, a velocidade é maior...

P: Então quer dizer que para um diâmetro de $4 \mathrm{~cm}$ a velocidade será a máxima?

A1: Acho que sim.

Mesmo com a validação via atividade experimental, A1 ainda coloca em dúvida o resultado encontrado. O que podemos ponderar, todavia, é que a produção de signos interpretantes não se finda com a finalização da atividade.

\section{Considerações finais}

Considerar a tecnologia como aliada no desenvolvimento de atividades de modelagem matemática vem ancorando pesquisas recentes na área de Educação Matemática. O que investigamos, todavia, é como a tecnologia se configura como recurso semiótico quando se faz presente no desenvolvimento de uma atividade de modelagem matemática. Ou seja, quando está presente na produção de signos e, em específico, de signos interpretantes.

$\mathrm{Na}$ intenção de mobilizar e mesmo estimular os alunos a trabalhar com uma atividade experimental investigativa no contexto da Modelagem Matemática, o professor solicitou que os mesmos movimentassem um copo situado sobre uma bancada do laboratório do lado oposto em que estavam. A partir do entrave vivenciado, o professor então apresenta um artefato construído com funil e luva de látex fazendo com que os alunos identifiquem uma maneira de aumentar a velocidade do ar para então movimentar o copo.

Defronte desta situação, um vídeo obtido da internet que trata da construção e dos mecanismos de funcionamento do Canhão de vórtex é apresentado de modo a inteirar os alunos da situação a ser investigada. O vídeo se configura como recurso semiótico que possilita produção de signos voltados para examinar os princípios envolvidos no Canhão de vórtex e mobilizar os alunos à definição de um problema relativo à velocidade de saída do ar do canhão de acordo com o orifício.

Para apresentar uma solução para o problema, a matematização se fez necessária na produção de dados empíricos que foram obtidos com o auxílio de uma filmadora. Essa tecnologia se configurou como recurso semiótico por possibilitar a visualização do fenômeno por mais de uma vez e, consequentemente, proporcionar sua análise, bem como 
uma fonte da qual se poderia produzir os dados. Tal produção de dados foi potencializada pelo software Trackerque permitiu determinar a localização de cada anel de fumaça de acordo com o tempo, com base em um sistema de eixos ortogonais.

A resolução empreendida pelos alunos para a atividade de modelagem foi realizada por meio de tratamentos dos dados, resultando na velocidade média para cada Canhão de vórtex. Com isso, realizaram uma abordagem no Microsoft Excel com vistas a representar graficamente os valores das velocidades médias de acordo com o orifício de cada canhão. Esse software se constitiuem um recurso semiótico que proporcionou uma visualização do comportamento dos dados no plano cartesiano e da função polinomial de segundo grau que os alunos ajustaram aos pontos. O signo algébrico produzido pelo Microsoft Excel foi essencial para a obtenção de uma solução para o problema.

De posse da solução, os alunos realizaram uma interpretação e validação. Especificamente a validação foi realizada pelo desenvolvimento da atividade experimental investigativa, considerando o tamanho do orifício obtido via modelo matemático. A análise da situação foi realizada por meio de filmagem e produção de dados via software Tracker.

O que podemos evidenciar é que a tecnologia se fez presente nas diferentes fases de desenvolvimento da atividade de modelagem matemática Canhão de vórtexem alusão a sua função como recurso semiótico como destacado na Figura 9.

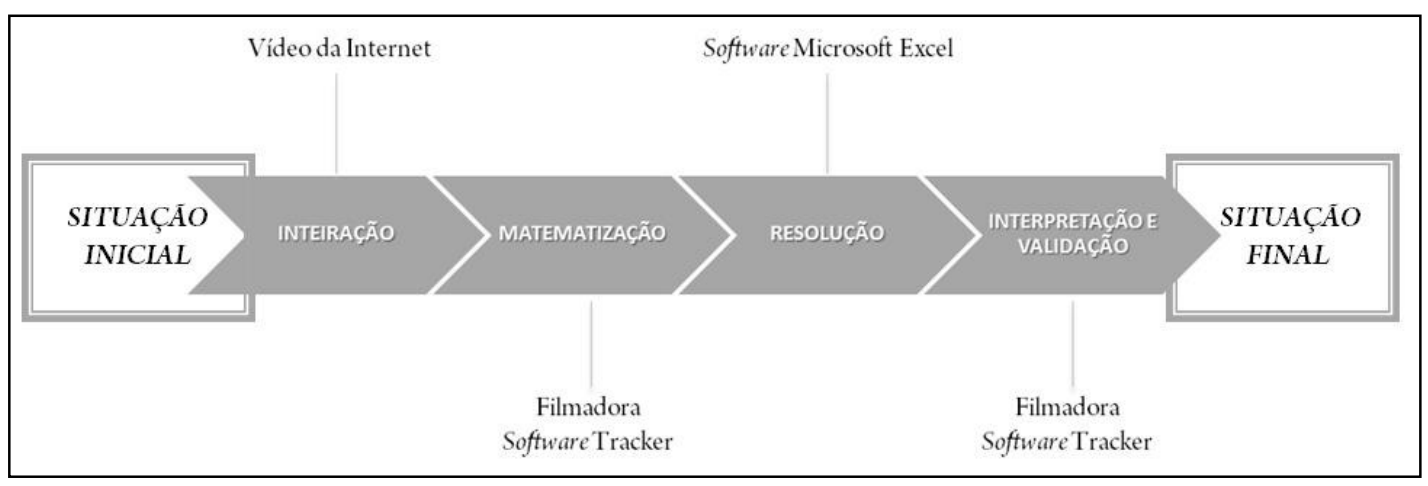

Figura 9: Esquema mostrando a presença da tecnologia nas diferentes fases da modelagem

Fonte: Dos autores

De fato, como sugerem Greefrath e Siller (2017):

Os alunos usam as ferramentas de maneiras muito diversas para pesquisar, construir, desenhar, calcular, medir, experimentar e visualizar. Para reforçar essas atividades em sala de aula, recomendamos também o uso de simulações que vinculem naturalmente a modelagem com o uso de ferramentas digitais. No entanto, mais pesquisas com uma ampla gama de dados e outros problemas de exemplo são necessários (GREEFRATH; SILLER, 2017, p. 537). 
De modo geral, a partir do recorte apresentado neste artigo, inferimos, por meio de umaanálise qualitativa de cunho interpretativo das imagens e das transcrições dasfalas nos cinco momentos de desenvolvimento da atividade de modelagem matemática, que a tecnologia se configurou como recurso semiótico, em certa medida, para possibilitar aos alunos examinar os princípios da situação-problema, definir o problema a ser investigado, visualizar o fenômeno mais de uma vez, produzir dados, visualizar o comportamento dos dados, proporcionando a obtenção, interpretação e validação de uma solução para o problema.

\section{Referências}

ALMEIDA, L. M. W.; SILVA, K. A. P.; RAMOS, D. C. Sobre ensinar e aprender 'o fazer' modelagem matemática. In: SEMINÁRIO INTERNACIONAL DE PESQUISA EM EDUCAÇÃO MATEMÁTICA, 7, 2018, Foz do Iguaçu. Anais... Foz do Iguaçu: SBEM, 2018. p. 1-12.

ALMEIDA, L. W.; SILVA, K. P.; VERTUAN, R. E. Modelagem Matemática na Educação Básica. 1. ed. São Paulo: Contexto, 2012.

BLEILER-BAXTER, S. K.; BARLOW, A. T. Moving beyond context: challenges in modeling instruction. In: NCTM. Mathematical Modeling and Modeling Mathematics. USA: APME, 2016. p. 53-64.

BLUM, W.; NISS, M. Applied mathematical problem solving, modelling, applications, and links toother subjects - state, trends and issues in mathematics instruction. Educational Studies in Mathematics, Netherlands, v. 22, n.1, p. 37-68, feb. 1991.

BOGDAN, R. C.; BIKLEN, S. K. Investigação qualitativa em educação - uma introdução à teoria e aos métodos. Porto: Porto Editora, 1994.

BROWN, D; COX, A. J. Innovative uses of video analysis. The Physics Teacher, v. 47, p. 145$150,2009$.

BRYAN, J. A. Investigating the conservation of mechanical energy using video analysis: four cases. Physics Education, London, v. 45, n. 1, p. 50-57, 2010.

CIRILLO M.; PELESKO, J. A.; FELTON-KOESTLER, M. D.; RUBEL, L. Perspectives on modeling in school mathematics. In: NCTM. Mathematical Modeling and Modeling

Mathematics. USA: APME, 2016. p. 3-16.

GREEFRATH, G.; SILLER, H.-S. Modelling and simulation with the help of digital tools. In: STILLMAN, G. A.; BLUM, W.; KAISER, G. (Eds.). Mathematical modelling and applications, ICTMA 17. Dordrecht: Springer, 2017. p. 529-539.

MANECHINE, S. R. S.; CALDEIRA, A. M. A. A significação e ressignificação da linguagem gráficana compreensão de fenômenos naturais. In: SEMINÁRIO INTERNACIONAL DE PESQUISA EM EDUCAÇÃOMATEMÁTICA, 3, 2006, Água de Lindóia. Anais... Água de Lindóia: SBEM, 2006. p. 1-16. 
MAVERS, D. E. Multimodal design: the semiotic resources of children's graphic representation. Doctoralthesis, Institute of Education, Universityof London, 2004.

MENDES, T. F.; OLIVEIRA, C. F. A inteiração e a matematização em atividades de modelagem matemática. In: SEMINÁRIO INTERNACIONAL DE PESQUISA EM EDUCAÇÃOMATEMÁTICA, 7, 2018, Foz do Iguaçu. Anais...Foz do Iguaçu: SBEM, 2018. p. $1-12$.

NETTO, M.; PERASSI, R.; FIALHO, F. A. P. Estudos semióticos: análise perceptiva e a terceiridade peirceana na obra "Jogos Infantis" de Pieter Bruegel. Projética, Londrina, v. 4, n. 1, p. 249-266, jan./jun. 2013.

PEIRCE, C. S. Semiótica. 3. ed. São Paulo: Perspectiva, 2005.

PEIRCE, C. S. Semiótica e Filosofia: textos escolhidos. São Paulo: Cultrix, 1972.

PIFFER, T. B.; BORSSOI, A. H. Modelagem Matemática em uma Sala de Aula de Física: relato de experiência. In: ENCONTRO PARANAENSE DE MODELAGEM NA EDUCAÇÃO MATEMÁTICA, 7, 2016, Londrina. Anais... Londrina: Universidade Estadual de Londrina, Universidade Tecnológica Federal do Paraná, 2016. p. 769-780.

SANTAELLA, L. Matrizes da linguagem e pensamento: sonora visual verbal: aplicações na hipermídia. 3. ed. São Paulo: Iluminuras: FAPESP, 2009.

SILVA, K. A. P.; BORSSOI, A. H.; ALMEIDA, LOURDES M. W. Uma análise semiótica de atividades de modelagem matemática mediadas pela tecnologia. Revista Brasileira de Ensino de Ciência e Tecnologia, Curitiba, v. 8, p. 161-183, 2015.

SILVA, K. A. P.; VERTUAN, R. E.; SILVA, J. M. G. Ensino por investigação nas aulas de matemática do curso de licenciatura em química. Amaz RECM - Especial Saberes Profissionais do Professor de Matemática, Belém, v.14, n. 31, p. 54-72, mar./out. 2018.

SILVA, M. B.; TRIVELATO, S. L. F. A mobilização do conhecimento teórico e empírico na produção de explicações e argumentos numa atividade investigativa de Biologia. Investigações em Ensino de Ciências, Porto Alegre, v. 22, n. 2, p. 139-153, 2017.

SUART, R. C.; MARCONDES, M. E. R. A manifestação de habilidades cognitivas em atividades experimentais investigativas no ensino médio de química. Ciências \& Cognição, Rio de Janeiro, v. 14, n. 1, p. 50-74, 2009.

THOMAS, M. O. J.; YOON, C.; DREYFUS, T. Multimodal Use of Semiotic Resources in theConstruction of Antiderivative. In: HUNTER, R.; BICKNELL, B.; BURGESS, T. (Eds.). Crossing divides: Proceedings of the $32^{\text {nd }}$ annual conference of the Mathematics Education Research Group of Australasia. Palmerston North, NZ: MERGA, 2009. p. 539-546.

VAN LEEUWEN, T. Introducing Social Semiotics. London \& New York: Routledge, 2005.

YOON, C.; MISKELL, T. Visualising cubic reasoning with semiotic resources and modeling cycles. In SÁENZ-LUDLOW, A.; KADUNZ, G. (Eds.). Semiotics as a tool for learning mathematics: How to describe the construction, visualisation, and communication of mathematical concepts. Dordrecht, The Netherlands: Sense Publishers, 2016. p. 89-109.

Recebido em: 18 de novembro de 2018.

Aceito em: 06 de dezembro de 2018. 